\title{
WHY HISTORICAL BECOMES PERSONAL? SPONTANEOUS HISTORICAL CONTENT OF INDIVIDUAL AUTOBIOGRAPHICAL MEMORY
}

\author{
Veronika V. Nourkova \\ Lomonosov Moscow State University \\ Moscow
}

Daniel M. Bernstein

Kwantlen Polytechnic University Surrey, BC

\begin{abstract}
In the present paper we suggest that people experience history from four perspectives: Participant, Witness, Contemporary and Successor. These perspectives differ in the proportion of experience, knowledge and personal meaning that is available. We empirically demonstrated greater malleability of memories about terrorist attacks that were experienced as a Witness than as a Contemporary. We also review research on the extent to which people spontaneously use historical events as a reference for dating personal memories. In our Moscow sample $(N=476)$, historical references were present in $5 \%$ of people. We found that $17 \%$ of participants listed historical memories in their life stories, as indicated by where they placed events along a Life Line. There was a tendency to balance negative historical experience with positive events from the Contemporary perspective (Gagarin'61, Olympic Games'80). Older participants included historical memories in their Life Lines more often than younger participants did, while the majority of historical memories referred to the age before 29. Participants recollected historical memories only from periods in their past that fell within what is called the "reminiscence bump" - a lifetime period that covers the age interval between 18-28 years. The proportion of historical content in individual autobiographical memory is determined by: 1) objective history; 2 ) experiencing historically transitional events in youth; 3) being older than the "reminiscence bump" period and 4) having at least a decade time distance toward historical event.
\end{abstract}

Keywords: autobiographical memory, historical memories, historical references.

This work was supported in part by a grant from President of the Russian Federation (MK - 2180.2008.6) to V.V.N. 


\section{The role of historical experience in individual autobiographical memory}

The American historian Henry Steele Commager once wrote that "History is organized memory, and the organization is all-important" (1966). If so, who organizes the memories that become history? For centuries the answer was historians who played to the interests of a very limited group of political elites. The situation dramatically changed in mid 20th century when Allan Nevins published The Gateway to History (1938). Nevins postulated that interviews with participants in recent history may serve as a basis for scientific research. In the 1970s Paul Thompson's The Voice of the Past (1978/2000) inspired many historians to go directly into the field to study oral history. Since then oral history as the "systematic collection of living people's testimony about their own experiences" (Judith Moyer, 1999) became a part of university studies. Moreover recently oral history was legitimized in court as being a source of evidence. For example, in 1997 the Supreme Court of Canada in the Aboriginal people v. British Columbia trial concluded that "oral histories should never be given any independent weight, but they are useful as confirmatory evidence" (Delgamuukw v. British Columbia, [1997] 3 S.C.R. 1010, \$ 98).

At present, there are hundreds of oral history collections that include personal stories about historical events (i.e. http://www.cyndislist.com/ oral.htm\#Libraries, http://memory.loc.gov/ammem/wpaintro/wpahome. html, http://www.iremember.ru, etc.). This shows that individuals remember not only their private personal experiences but also historical experiences - or those experiences with historical content. Why do these features exist in memory? We suggest that it is advantageous for a person to consider historical events as personally significant. We have identified at least five hypothetical reasons to include historical memories in one's own life story:

- to imbue daily routine with historical import;

- to provide temporal landmarks which define the periods of life (Brown et al., 2009);

- to form social solidarity and a cultural and national identity (Nelson, 2003);

- to be aware of oneself as part of a higher-order totality;

- to allow the person to feel himself as a creator of history; 
- to transfer responsibility for failures in private life, e.g., "I could have become a famous writer, but the political situation ruined my plans."

\section{A framework for understanding historical memories}

It is obvious that historians focus not on private personal experiences of interviewees but on the historical context they share with other people. Historians pretend to extract uniform "objective" historical truth from various personal experiences. Psychologists, conversely, believe that it is difficult, if not impossible, to dissociate "knowledge" and "experience." People examine their personal past through "lenses" of personal meaning. Therefore living recollections of historical events embody a mixture of subjective interpretations, knowledge, and images of the experienced historical event. In other words, historians ignore the fact that semantic knowledge and autobiographical memory are two different (but definitely corresponding) types of human cognition. Semantic knowledge is a store for personally neutral facts that do not affect the personal self (e.g., Paris is the capital of France). In contrast, autobiographical memory has been called a "self-memory system" (Conway \& Pleydell-Pearce, 2000; Conway, 2005). The latter means that one's current motives, goals and self-concept all determine perception, retention, rehearsal, reinterpretation, and recall of autobiographically relevant historic information.

When we examine historical aspects of personal experience, this involves retrieval from autobiographical memory. Donald A. Ritchie stated the problem in the foreword to his book Memory and History (1994): "Interviewees all tell their stories from their own subjective points of view. Their individual perceptions vary substantially, since not everyone had a clear view of what happened or a comprehensive understanding of what it meant. Generals in the rear may know the broad sweep of the battle plan, but foot soldiers will have a different view of the action on the battlefield; those at the center of events can proudly recount their own accomplishments, but those on the periphery are often better able to make comparisons between the principal actors" (p. vi).

Living their lives and being involved in global events, people may experience events from four psychological perspectives. We previously labeled these perspectives - Participant, Witness, Contemporary, and 
Successor (Nourkova, 2001a; Nourkova, 2001b; Nourkova, 2001c; Bernstein, Nourkova, \& Loftus, 2008; Nourkova, 2009).

Participant. Participants have direct involvement in and often experience intense stress during the event. Participants may focus on a particular aspect of their experience, while ignoring other details, thus failing to comprehend the event's larger meaning. Leo Tolstoy correctly described this in his famous scene of the Borodino battle in War and Peace: participants not only see fragmentarily, but they may also lack the perspective to appreciate what is happening on a larger scale, despite the vividness and immediacy of their experience. Therefore, Participants actively seek information to compensate for its scarcity. In one of the most famous Russian poems Borodino Lermontov expressed the perspective of an old soldier recollecting past times: "Retreating this day and the next, / We wonder'd when's our battle, vex'd ; / The veterans talk'd upset: / 'What then? we're off to winter dorms? / Go the commanders by new norms; / Daren't they rip foreign uniforms / On Russian bayonet?"”

Witness. Witnesses view the event at a distance. Witnesses are physically present but they are not directly involved in the event. As with Participants, Witnesses may still have insufficient information about the entire event to clearly understand its meaning. Despite this lack of understanding, the Witness often feels very well informed about the event. There is a popular saying, "Lie as a Witness." To achieve greater authenticity, Witnesses may pretend to be Participants, thus searching for intensive personal meaning in the event. Returning to Lermontov's poem, "Borodino": "The lancers in their motley guise, / Dragoons with horse-tails with loud cries - / They all would flash before our eyes, / They all were near about."

Contemporary. Contemporaries do not witness or participate in the event, but they are alive when the event occurs. Contemporaries typically learn about the event from the media, be it television, radio, newspapers, gossip etc. Before new media technologies were invented, Contemporaries relied entirely on second-hand reports of the event. Now Contemporaries may experience the event "in real time" via new media technologies like Twitter and Facebook as if they were present at the event, but without the concomitant risks that Participants and Witnesses 
face. However, Contemporaries often seek more experience in the form of tourism, historical games, museums, etc. Doing so, Contemporaries create and live with an illusion of direct involvement in the historical event.

Successor. Successors are not alive when the event occurs. Successors obtain their collective memories through historical documents. Due to their reliance on the media, Successors and Contemporaries are particularly vulnerable to whatever version of the event that the media wish to present. There are many examples of the power of images to shape both memory and history. Hollywood films like Spartacus, Cleopatra, and Robin Hood give the historical figure a face. As a result, our collective memory is littered with images of Kirk Douglas as Spartacus, Elizabeth Taylor as Cleopatra, and Russell Crow as Robin Hood.

It is reasonable to distinguish between two forms of Successor: One involves the relatively recent past and the other involves the distant past. In the former case, the Successor often has an opportunity to interact directly with family members who are themselves Participants or Witnesses (these family members are usually grandparents), who share their experience. In the example described above, the poem started with a scene in which a young soldier asked an elder to tell him a story about Borodino: "HEY tell, old man, had we a cause / When Moscow, razed by fire, once was / Given up to Frenchman's blow? / Old-timers talk about some frays, / And they remember well those days! / With cause all Russia fashions lays / About Borodino!" There is an interesting phenomenon of psychological participation, which follows the logic: "I am a part of my ancestry, so my ancestors' experience is partly my experience." An illustration of this powerful feeling can be seen in the story of how Moscow's youth took to the streets in 2007 with the slogan "Our grandparents' victory is our victory." The youth were protesting against the replacement of soldiers' graves in Estonia. In the case of Successors who obtain their knowledge from the distant past, they do not have the opportunity to interact with Participants or Witnesses, and therefore must rely solely on media sources.

Figure 1 shows the interactions among the Witness, Participant, and Contemporary perspectives. From each perspective, the person has two forms of memory located to his / her left and right, and is seeking the third form of memory, located at a 45-degree angle from him / her. For 


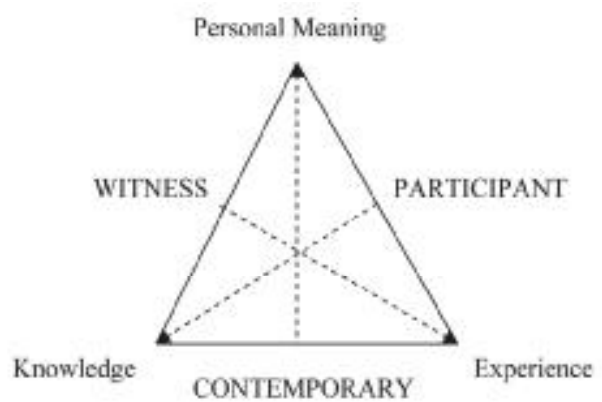

Figure 1. 3-dimensional model of historical memory.

instance, the Witness has Personal Meaning (he was there personally, it influenced his life) and Knowledge (he learned about it from the media), but lacks Experience (he didn't participate actively). The Participant has vivid Experience and Personal Meaning, but lacks objective Knowledge. Finally, the Contemporary has Knowledge and Experience, but lacks Personal Meaning. Moreover, the Contemporary derives experience of an event from both private and public sources (i.e. "I was setting the dinner table for a party when I saw WTC bombing on TV; the party was ruined"). For the Contemporary, media coverage of an event often serves as a substitute for Personal Experience.

In contrast to the three perspectives depicted in Figure 1, the Successor lacks all three components of living memory. Instead, the Successor may assume the Witness, Participant, or Contemporary perspective by employing non-personal sources of information. Objectively speaking, the Successor is absent from Figure 1, because he / she lacks Experience, Personal Meaning, and Knowledge. Psychologically speaking, though, the Successor may occupy any of the three perspectives depicted in Figure 1.

It is important to note that sometimes there is a discrepancy between physical position and psychological perspective. For instance, as the historian, Ritchie, notes, the general leading a battle may feel himself as a Participant of the battle ("And eyes aflame, he spoke his mind: / 'Hey lads! is Moscow not behind? / By Moscow then we die / As have our brethren died before!"') or as a distant Witness of a scene ("The steeds, the men all disassembled, / And cannon volleys' sound resembled / A moaning oer the land" Lermontov, Borodino). 


\section{Terrorist attacks recollected from the Contemporary or Witness psychological perspective}

We have conducted two consecutive studies, six months apart, to examine the proposed framework (Nourkova, Bernstein, \& Loftus, 2003; Nourkova, Bernstein, \& Loftus, 2004). Subjects of both studies were Moscow residents $(\mathrm{N}=91)$. The Moscow sample was chosen because they provided a unique opportunity to examine people's memories for two different events that were personally and historically significant. The first event involved two separate terrorist bombings that occurred in two Moscow apartment buildings, one on September 9 (12:00 a.m.), and another on September 13 (5:05 a.m.), 1999. The second event involved the terrorist attacks on the World Trade Centers (8:45 a.m. and 9:03 a.m.) in New York City on September 11, 2001. The Moscow attacks claimed 233 lives, while the World Trade Center (WTC) attacks claimed nearly 3000 lives.

The Moscow attacks were highly personally relevant to the Russian sample, but these attacks were not of great historical significance. Conversely, the WTC bombings were less personally relevant to the Russian sample, but were of great historical significance. We hypothesized that for residents of Moscow, the WTC attacks involved the Contemporary perspective, but the Moscow attacks involved the Witness perspective. We thought it would be useful to examine how individuals within the Contemporary perspective and within the Witness perspective might respond to two events. We were interested in recollection differences generally and malleability of historical memories specifically.

In the first study we asked subjects to complete a questionnaire exactly six months after the WTC bombings. We asked subjects to rate their recollections about the first event that came to mind with the cue, "tragic public event in September." Using a 1 (very low) to 5 (very high) scale, subjects rated their memory for this event in terms of its vividness, number of details, confidence and personal and historical meaning. Ninety percent of the respondents recalled the WTC case first. After they completed these questions, subjects were asked to do the same for the Moscow case. This procedure allowed us to compare subjects' responses for the WTC and Moscow terrorist attacks.

In accordance with our predictions the Moscow event was more personally significant to the Russian sample than was the WTC attack. 
Subjects rated the Moscow event as more personally significant than the WTC event (mean 2.94 Vs. 1.83). They suggested that the Moscow bombings were the topic of daily conversation for twice as long as the WTC attack. Additionally, subjects rated the strength of emotion evoked by the Moscow event as higher than the strength of emotion evoked by the WTC event (mean 4.28 Vs. 3.70, for Moscow and WTC, respectively). Finally, the Moscow event tended to evoke fear (48\%), horror (28\%), shock (14\%) and anger (12\%), while the WTC attack evoked responses like "beyond belief" (29\%), sadness (27\%) and surprise (21\%).

Generally, our Moscow subjects recalled the two events differently. For the personally relevant Moscow bombings (Witness perspective), subjects included more actions and emotional detail in their descriptions of the events: "Explosion, people shouting, clouds of smoke, corpses on a stretcher, wounded people stained with blood, the shaking body of a victim. Nobody sleeps. People run out from houses onto the streets." In contrast, for the less personally relevant but highly historically relevant WTC attack (Contemporary perspective), subjects' descriptions were rather matter of fact: "The passenger plane was hijacked by terrorists; it crashed into a skyscraper; there was a huge explosion; a building collapsed; thousands of people were lost." Moreover, subjects tended to use different verb tenses when describing the two events. Subjects mainly used the present tense for the Moscow bombing, while they used the past tense for the WTC bombing. These results indicate that the Witness and Contemporary perspectives were associated with different experiences and recall strategies. However, there were some commonalities in how subjects from these two different perspectives (Witness and Contemporary) recalled the events. In particular, subjects overestimated the duration of both events. Subjects overestimated the duration of the WTC and Moscow bombings by $40 \%$ and $26 \%$, respectively. Finally, $37 \%$ of the subjects mistakenly reported that the WTC attack occurred in the afternoon. This finding is likely due, in part, to the 11 -hour time difference between Moscow and New York.

In the second study conducted six months later we tested the hypothesis that the same people as Witnesses are more susceptible to memory distortion than as Contemporaries. Subjects were randomly assigned to answer questions about the WTC bombings (WTC Memory group) or about the Moscow bombings (Moscow Memory group). People were asked this question: "Half a year ago, when you were taking part in our 
study you mentioned a wounded animal. Do you remember it?" Subjects were asked to provide as much information as they could remember. None of the subjects in either group mentioned a wounded animal during the first study. Nonetheless, after receiving the strong suggestion that they had mentioned this detail, five Moscow Memory subjects (12.5\%) accepted the suggestion that they had seen and previously recalled a wounded animal during the Moscow bombings. Conversely, none of the WTC Memory subjects accepted this suggestion $\chi^{2}=5.0, \mathrm{p}<.05$. While $12.5 \%$ is not much, it does show that it is possible with only a small suggestion to create aspects of memories for a traumatic event like the Moscow bombings.

These results show the higher malleability of memory for historically significant events experienced as Witness than as Contemporary. Compared with the more historically relevant WTC bombings, the Moscow bombings tended to evince more emotion in our Moscow sample. Moreover, our subjects' descriptions of the Moscow attacks were more chaotic than were their descriptions of the WTC attacks. It is possible that the personal relevance of the Moscow attacks clouded their perception and subsequent memories for the event. These findings help delineate the link between memories for personally and historically relevant events.

\section{Historical references in dating autobiographical episodes}

In most studies devoted to the presence of historical information in one's personal memory, an interviewer asks subjects to try to recollect specific historical events (e.g., the day that Allied forces liberated Europe from Nazi occupation). Obviously, cueing subjects to recall details of specific events may result in greater recall of those cued events (e.g. Schuman \& Rogers, 2004; Nourkova, 2008).

But what happens if the interviewer fails to mention the word, "history" during the autobiographical interview? Would the interviewee mention historical events spontaneously when discussing his or her private past? In other words, how often do people spontaneously include historical information in their private life stories? Are people aware of the historical context of their lives, or how historical events shape who we are? Does awareness of this historical context grow with age? Are there age and gender differences in sensitivity to historical context? 
We start this section with a brief description of the Living-in-History Project cross-national research program (Brown et al., 2008; Brown \& Lee, in press). The leader of the project N.R. Brown and his collaborators wish to know when and why significant public events create and delineate historically-defined autobiographical periods. They introduced the term "historical reference" to describe the case when people use historical events as a way of dating their personal experiences. They considered the implications of 11 data sets from various countries (Sarajevo, Bosnia-Herzegovina; Belgrade, Serbia; Podgorica, Montenegro; Izmit, Turkey; Ankara, Turkey; New York City, NY, USA; Ann Arbor, MI, USA; Jerusalem, Israel; Aalborg, Denmark; Edmonton, AB, Canada; Moscow, Russia $^{1}$ ).

Brown has developed an original two-stage procedure. Stage 1 consists of cueing autobiographical recollections by 20 neutral cue words (e.g. pencil, radio, spoon, and piano). Immediately after that during Stage 2 subjects think aloud as they date each recollection. The researchers examined information used to reconstruct dates of past episodes and considered the prevalence of the historical references in the dating protocols as an index of the degree to which historically-significant public events affect people's lives. For instance, as a response to the cue word, "pill," a subject reported the episode, "When my mom took a sedative pill." The subject then verbalized how he dated this event by reporting, "This was during war times. It was during those fearful times and all that horror. 1995 maybe, thought it happened throughout all those years. I remembered that one specific night when it was the worst. Month I can't remember. I have no idea. Any one, April?" (Montenegro). In Brown's terms "war times" is a case of historical reference. In contrast, another participant used a personal reference for the episode cued by he same word "pill," "That was after my wisdom teeth were pulled when I was 21 " (Michigan).

The following claims were made as an outcome of the Living-in-History Project:

- Historical references are the exception rather than the rule.

- Historical references are formed in people who have lived through intense and / or prolonged conflict.

1 For Russian sample the data were collected by V.V. Nourkova. 
- Major natural disasters also spawn historical references in the affected population.

- Historical references are formed in children as well as teen-agers and young adults who have lived in conflict zones.

- Once formed, historical references last a lifetime.

- The historical references effect is temporally limited.

- The historical references effect is intensity graded.

- Political upheaval does not produce a robust historical references effect.

- Terrorist attacks do not create historical references.

In a Moscow sample, from 500 dated recollections only 24 had historical references (see Table 1). Historical references were present in less than $5 \%$ of the date estimates, and about a third of these concerned the perestroika period. The majority of these Historical references (except $60^{\text {th }}$ Victory Day) were negative. The Moscow sample was similar to the rest of the data in terms of negativity of the historical context; however, the Moscow sample had a lower level of historical references in comparison with Sarajevo (24\%) or Izmit (14\%).

Table 1

Historical references in dating personal autobiographical memories

\begin{tabular}{|l|l|c|c|}
\hline \multicolumn{1}{|c|}{ Historical event } & \multicolumn{1}{|c|}{ Date } & $\begin{array}{c}\text { Number of } \\
\text { references }\end{array}$ & $\%$ \\
\hline Perestroika & $1985-1991$ & 7 & 29.1 \\
\hline Default & August, 1998 & 5 & 20.8 \\
\hline Putch & August, 1991 & 3 & 12.5 \\
\hline Collapse of USSR & August, 1991 & 1 & 4.1 \\
\hline Chernobyl & April, 1986 & 1 & 4.1 \\
\hline Chechenian War & 1993 & 1 & 4.1 \\
\hline Elections Duma & 2007 & 2 & 8.3 \\
\hline Brezhnev's death & 1982 & 1 & 4.1 \\
\hline Cooperative movement & 1987 & 1 & 4.1 \\
\hline Pavlov's financial reform & 1990 & 1 & 4.1 \\
\hline $60^{\text {th }}$ Victory Day & May, 2005 & 1 & 4.1 \\
\hline Sum & & 24 & 100 \\
\hline
\end{tabular}




\section{Empirical study of spontaneous tendency to include historical events in one's autobiographical memory}

In our next study we focused on the historical content of personal life stories. We conducted the study to examine factors that people use when considering historical events as a significant part of their personal past.

476 participants took part in the study (167 males (35\%) and 310 females (65\%), 23\% of them 18-30 years old, $34.6 \% 31-45$ years old, $31 \%$ $46-60$ years old, and $11.4 \% 61-88$ years old).

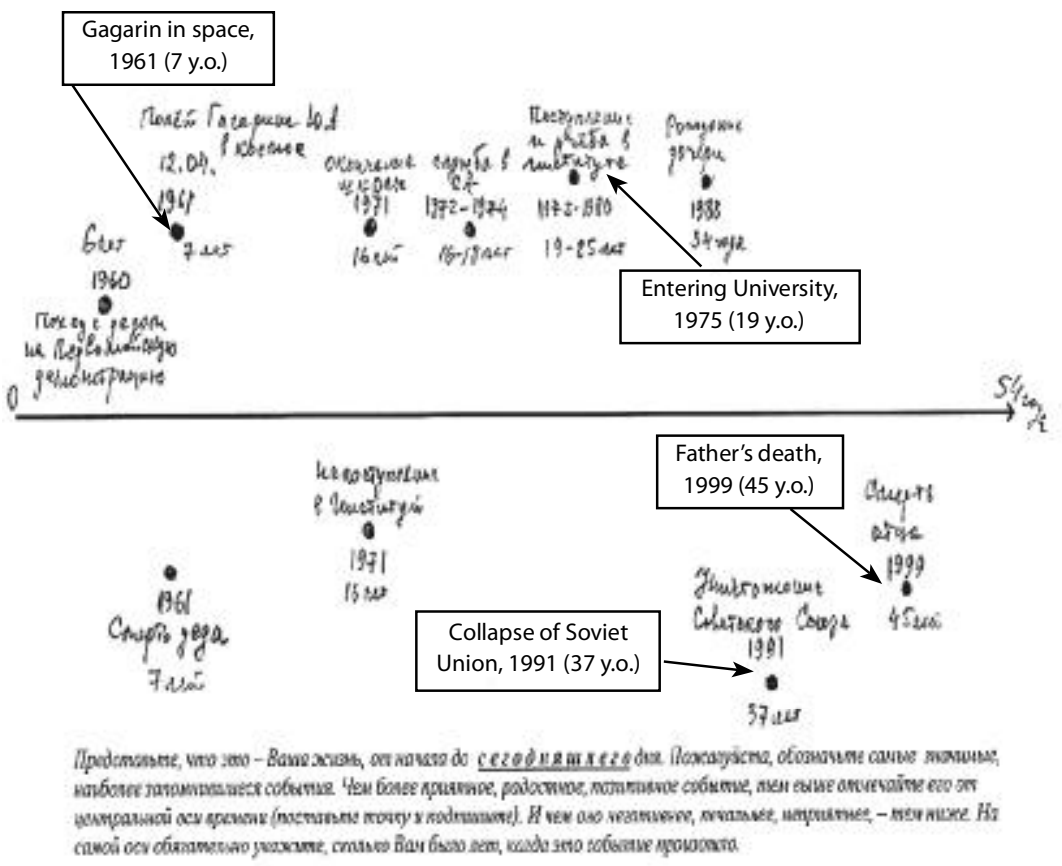

Figure 2. Protocol obtained from a 54 year-old male. The instruction was the following: "Imagine that this sheet is your own past. Put here the most memorable events of your past, noticing the age when they happened and the emotion you experienced. Express your emotions by the distance from middle arrow." The subject put the historical event, "Collapse of Soviet Union" as the worst memory from his personal past. It is more negative than the personal event, "Father's death." The historical event, "Gagarin in space" and the personal event, "Entering University" are the same positive emotional intensity. 
Participants received a standard horizontal sheet of paper with an arrow in the middle with instruction "Put here the most memorable events of your past, noticing the age when they happened and the emotion you experienced." There were no historical references in the instruction. In contrast to the previous research we examined the life story as a whole, so we expected that only the most significant memories would be listed. An example of a protocol obtained from a 54-year old male is presented in Figure 2.

The first outcome of our study was that $16.5 \%$ (78) of participants spontaneously included historical events in their Life Line pictures of private events such as "marriage" or "birth of children." As is evident in Figure 2, emotional intensity of historical memories expressed graphically by the distance from the time line is equal to emotional intensity of private memories.

People mostly included negative historical memories in their autobiographical memory (72.1\%). Figure 3 depicts the proportion of historical events that participants included in their Life lines.

The most common historical memories (WWII, Perestroika, Putch, Collapse of USSR and 1998 Financial default) appeared in protocols because of their direct, forceful, prolonged and catastrophic effect on daily life. That set of data is consistent with Brown's statements about the

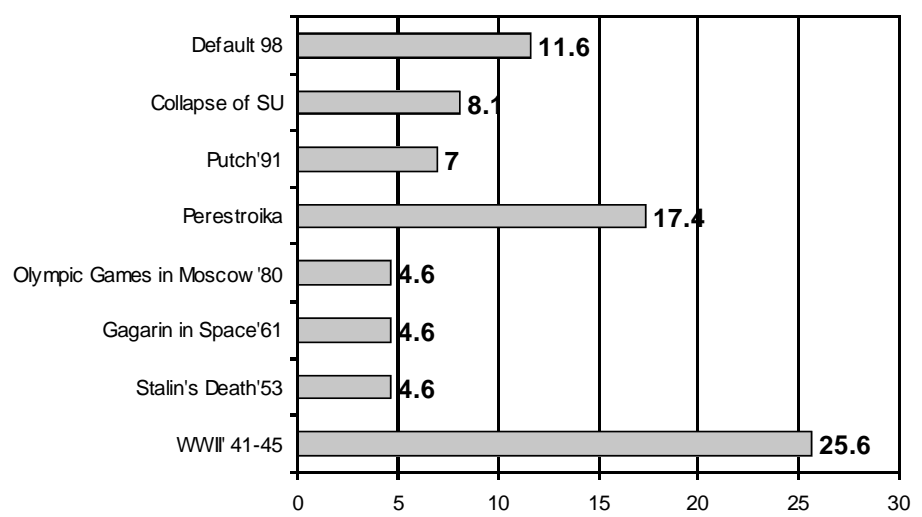

Figure 3. History of Russia as a part of personal life stories $(\mathrm{N}=476)$. Percentage of historical events spontaneously included in protocols. The sum is less than $100 \%$, because events mentioned once in the sample were not included. 
prevalence of negative historical references in autobiographical memory. In contrast to Brown's results we found that positive historical events (Gagarin'61, Olympic Games'80) also were in subjects' Life Lines. There were no astronauts or sportsmen in the sample, so those events were experienced from the Contemporary perspective. We speculate that the rationale behind that is a positive symbolic impact of those events. In other words, there is a tendency to balance negative historical events experienced from the Participant and Witness perspectives with highly positive events experienced from the Contemporary perspective.

We found that participants who included historical events in their autobiographical memory were significantly older $(t=10.08, p=0.000)$. This difference is not surprising given that historical memories referred mostly to youth and early adulthood. As is shown in Figure $4,50 \%$ of spontaneous historical memories referred to one's age before $20 ; 75 \%$ of spontaneous historical memories referred to one's age before 29 . There were few historical memories that referred to one's age after 45 . There were no historical memories that referred to one's age after 63 (we had 56 participants older than 63).

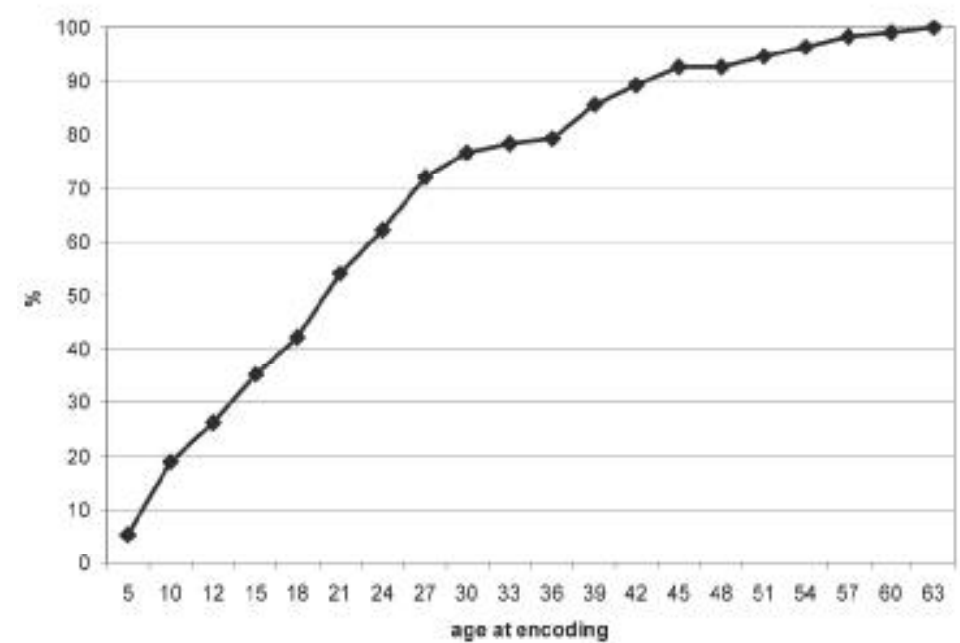

Figure 4. Cumulative distribution depicting the age of historical memories reported spontaneously in our sample of 476 participants. 


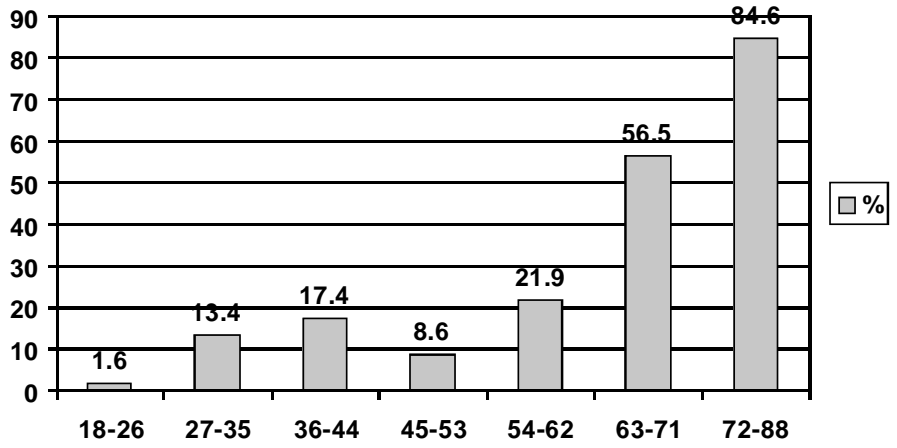

Figure 5. Percentage of people who spontaneously included historical events in their Life Lines by age (differences are significant at $p<.05$, except $27-35$ vs 36-44).

To examine the sensitivity to history in different ages, we divided the sample into seven age groups: $18-26 ; 27-35 ; 36-44 ; 45-53 ; 54-62 ; 63-71$ and 72-88 (see Fig. 5). The groups were significantly different in terms of the number of people who spontaneously included historical events in their Life Lines (ANOVA $F=47.801, d f=7, p=0.000$ ). Surprisingly, middleage participants (45-53) reported fewer historical recollections than 36-44 and 54-62 groups (ANOVA $F=28.33, d f=3, p=0.000$ ). It is obvious that middle-age participants did not experience as many transitional historical events as the 63-88 generations did (e.g. WWII), even though these transitional historical events were equal in availability to the next closest age groups of 36-44 or 54-62. What is special about the 45-53 age group?

To answer this question, let's look at the ages when the 45- to 53- and the 36- to 44-year-old participants experienced historical events that occurred during their life time (Table 2). The 36- to 44-year old participants were 8-16 years of age when the Olympic Games at Moscow took place; they were 14-22 years of age when Perestroika prepared political system change; they were 19-27 years of age when the Putch tried to return the "good old times" and the USSR collapsed, and they were 26-34 years of age when financial default threatened economic prosperity. For the same set of events participants now 45-53 years of age were respectively in the ages $17-25 ; 23-31 ; 28-36$ and $35-43$. In other words, participants from the 36-44 group experienced all five of the five most often mentioned 
historical events during the period typically reported to coincide with what is called the "reminiscence bump," (16-28 years of age) while participants from the 45-53 group only experienced two of these events coinciding with the reminiscence bump.

The "Reminiscence Bump" for autobiographical memories was discovered by Rubin, Wetzler, and Nebes (1986) in a reanalysis of data from several studies on word-cued memories and has been replicated numerous times (e.g., Rubin \& Schulkind, 1997). The core of the effect is that the distribution of memories across the life span deviates from a monotonically decreasing curve by showing an increase in reported memories from the second and third decades of life. Rubin et al. argued that an adequate description of the life span distribution of autobiographical memories has three components: a retention function to account for the decrease in frequency of memories as a function of time since the event occurred, a childhood amnesia component, and the bump (see also Rubin, Rahhal, \& Poon, 1998). The most common explanation for the bump has centered on the formation of an adult identity in young adulthood. According to this explanation, the bump reflects the way our life narratives are organized. Rubin and Berntsen (2004) postulated and empirically investigated "cultural life scripts" that determine among other things the most memorable period of human life (16-28 years of age on average). In our opinion, the reminiscence bump effect should be expanded to include historical memories just as it has been demonstrated widely for private memories.

Table 2

Age of experiencing historical events for two groups of participants. RB - Reminiscence Bump period

\begin{tabular}{|c|c|c|c|c|c|}
\hline \multirow{3}{*}{ Group } & \multicolumn{5}{|c|}{ Event } \\
\cline { 2 - 6 } & $\begin{array}{c}\text { Olympic } \\
\text { Games'80 }\end{array}$ & Perestroika'86 & Putch'91 & $\begin{array}{c}\text { Collapse of } \\
\text { USSR'91 }\end{array}$ & Default'98 \\
\hline $36-44$ & $\begin{array}{c}8-16 \\
+\mathrm{RB}\end{array}$ & $\begin{array}{c}14-22 \\
+\mathrm{RB}\end{array}$ & $\begin{array}{c}19-27 \\
+\mathrm{RB}\end{array}$ & $\begin{array}{c}19-27 \\
+\mathrm{RB}\end{array}$ & $\begin{array}{c}26-34 \\
+\mathrm{RB}\end{array}$ \\
\hline \multirow{2}{*}{$45-53$} & $\begin{array}{c}17-25 \\
+\mathrm{RB}\end{array}$ & $\begin{array}{c}23-31 \\
+\mathrm{RB}\end{array}$ & $28-36$ & $28-36$ & $35-43$ \\
\hline
\end{tabular}

Finally we looked at time distance between historical events and day of retrieval. We found very few historical memories from the last decade $(<10 \%)$ with no correspondence with the actual age of participants. 


\section{Conclusions}

We began our discussion with an overview of the functional role of memories about historically significant events as a kind of personal, individual memory. We identified reasons for considering historical events as personally important and we argued that historical memory be included as a part of autobiographical memory. In our opinion, the most important facets of historical memories are: increasing the value of daily routines; organizing the temporal scale by using historical landmarks; awareness of oneself as a part of a higher-order social totality; symbolizing the achievements of one's cultural and national group identity and feeling oneself as an active creator of history.

We then broadened our focus to introduce the proposed framework for understanding psychological perspectives toward historical events. We suggested that people experience history from four partly interconnected perspectives: Participant, Witness, Contemporary and Successor. Those perspectives differ in the proportion of experience, historical knowledge and personal meaning in recollection. From each position the person has only two components of complete memory. The Participant's recollection is complete in experience and personal meaning, but poor in historical knowledge. The Witness's recollection is complete in historical knowledge and experience, but poor in personal meaning. The Contemporary's recollection is complete in historical knowledge and personal meaning, but poor in experience. Successors form historical memories about events that happened before their birth, so they have all three components (experience + personal meaning + historical knowledge). Each perspective has its own advantages and disadvantages. The person afforded any one of these vantage points will attempt to strike a balance between experiential and factual information. No one perspective is immune to memory distortion. In fact, all four perspectives and their resulting memories are prone to systematic biases and errors.

In the next section of the paper we empirically examined whether historical memories about terrorist attacks that were experienced from the Witness or Contemporary perspectives were susceptible to distortion. 91 undergraduate students at Moscow State University recollected the WTC bombings on 9/11/2001 and the bombings of two Moscow apartment buildings, one on September 9 and another on September 13, 1999. We proposed that for residents of Moscow the WTC attacks involved the 
Contemporary perspective, while Moscow attacks involved the Witness perspective. Our findings demonstrate that historically significant events experienced from the Witness perspective are more malleable than those experienced from the Contemporary perspective. In comparison with the Contemporary perspective, the Witness perspective tended to evoke more emotion in our Moscow sample. Also, our subjects' descriptions of the Moscow attacks were more chaotic than were their descriptions of the WTC attacks.

The fourth section of the paper dealt with historical references in dating personal autobiographical episodes. We overviewed the crossnational research program, investigating the presence of historical context as a dating strategy in autobiographical memory. After interviewing participants from 9 countries, the authors (N.R. Brown et al.) concluded that historical memories became a part of autobiographical memory only when public events dramatically altered the fabric of daily life, for a population, for an extended time period. In our view, the main advantage of the research procedure developed for that program is an avoidance of direct instruction to recollect specific historical events. This procedure made it possible to focus on historical aspects of autobiographical memory, rather than overall knowledge about history. In the Moscow sample, historical references were present in less than $5 \%$ of the justified date estimates, and about a third of these concerned the perestroika period. The vast majority of historical references in the Moscow sample (with the exception of $60^{\text {th }}$ Victory Day) was negative. The Moscow sample was similar to the rest of the data in that people provided mostly negative historical context in their memory reports. The Moscow sample did, however, provide a much lower level of historical references in comparison with Sarajevo (24\%) or Izmit (14\%).

In the last section of the paper we present the results of our empirical study. We examine if people spontaneously include historical information in their private life stories $(\mathrm{N}=476)$. In contrast to Brown's study we collected the graphic presentations of one's life story as a whole, speculating that only the most personally significant memories are put into such "Life lines." People were asked simply to put the most memorable events of their past into the picture. There was no mention of "history" in the instructions. We found that in contrast to Brown's study, in which Russian people provided $5 \%$ of historical references, almost $17 \%$ of participants in our study included historical events in their Life Line pictures. People 
mostly included negative historical memories in their autobiographical memory $(72.1 \%)$. We noted the positive symbolic impact that historical events played in people's lives without directly influencing daily routine (Gagarin'61, Olympic Games'80). We interpreted this as a tendency to balance the negative historical events experienced from the Participant and Witness perspectives with the highly positive events experienced from the Contemporary perspective.

As a general rule older participants had more historical memories in their Life Lines. Only 1.6\% of participants at 18-26 years of age reported historical memories when asked to report the most memorable events of their past. In contrast, $84.6 \%$ of participants from the oldest group (72-88 years of age) reported historical memories. We noticed that $75 \%$ of spontaneous historical memories referred to the age before 29 , and few historical memories referred to the age after 45 . We demonstrated that although participants experienced the same set of historical events similarly in terms of the impact that these events had on their lives, they often included very different details in their reports of these experiences. Participants spontaneously included historical memories in their Life Lines, and these memories often fell within the ages associated with the "reminiscence bump." Finally we found few historical memories reported from the last decade of one's life $(<10 \%)$, and this fact did not correspond to the actual age of participants.

We conclude that the presence of historical events as a part of individual autobiographical memory is determined by: 1) the objective history of the country; 2) experiencing historically transitional events in youth; 3 ) being older than 30 ("reminiscence bump" period) and 4) recollecting the historical events having at least a decade time distance.

\section{References}

Bernstein, D.M., Nourkova, V.V., \& Loftus, E.F. (2008). From Individual Memories to Oral History. In A.M. Colombus (Ed.), Advances in Psychology Research, 54 (pp. 157-181). New York: Nova Science Publishers.

Berntsen, D., \& Rubin, D.C. (2004). Cultural Life Scripts Structure Recall from Autobiographical Memory. Memory \& Cognition, 32, 427-442.

Brown, N.R., \& Lee, P.J. (In press). Public Events and the Organization of Autobiographical Memory: An Overview of the Living-in-History Project. Behavioral Sciences of Terrorism and Political Aggression. 
Brown, N.R., Lee, P.J., Krslak, M., Conrad, F.G., Hansen, T., Havelka, J., \& Reddon, J. (2009). Living in History: How War, Terrorism, and Natural Disaster Affect the Organization of Autobiographical Memory. Psychological Science, 20, 399-405.

Commager, H.S. (1966). The Study of History. Columbus: C.E. Merill.

Conway, M.A. (2005). Memory and the Self. Journal of Memory and Language, 53 (4), 594-628.

Conway, M.A., \& Pleydell-Pearce, C.W. (2000). The Construction of Autobiographical Memories in the Self Memory System. Psychological Review, 107, 261-288.

Delgamuukw $v$. British Columbia, [1997] 3 S.C.R. 1010 http://scc.lexum. umontreal.ca/en/1997/1997scr3-1010/1997scr3-1010.html

Halbwachs, M. (1992). On Collective Memory. University of Chicago Press.

Jeffrey, J., \& Edwall, G. (Eds.). (1994). Memory and History. Essays on Recalling and Interpreting Experience. Boston: University Press of America.

Nelson, K. (2003). Self and Social Function: Individual Autobiographical Memory and Collective Narrative. Memory, 11 (2), 125-136.

Nourkova, V.V. (2001a). Istoričeskoe sobytie kak fakt avtobiografičeskoj pamâti [Historical Event as a Fact of Autobiographical Memory]. Voobražaemoe prošloe Ameriki [Imagined Past of America (3rd summer school of American studies)] (pp. 20-34). Moscow: MAX Press.

Nourkova, V.V. (2001b). Istoričeskaâ pamât' - avtobiografiâ sovremennosti [Historical Memory - the Autobiography of Modern Times]. In Socialnye i psihologičeskie problemy mentaliteta na rubeže stoletij [Social and Psychological Problems of Mentality on the Borders of Centuries] (pp. 93-98). Smolensk: SGU.

Nourkova, V.V. (2001c). "Čelovek putešestvuûsîij." Geografiâ i avtobiografiâ. [The Traveler. Geography and Autobiography]. Vestnik istoričeskoj geografii, 2, 65-87.

Nourkova, V.V. (2008). History as a Component of Personal Past in Old and Young Russians. Poster presented at the 19th International Congress of the International Association for Cross-Cultural Psychology. Bremen, Germany.

Nourkova, V.V. (2009a). Istoriâ kak ličnyj opyt [History as a Personal Experience]. Istoričeskầ psihologiâ $i$ sociologiâ istorii, 1, 5-28.

Nourkova, V.V. (2009b). When Historical Becomes Personal? Age at Encoding and Temporal Distance Predict Sensitivity to Historical Memories. Paper presented at the $8^{\text {th }}$ Biennial Meeting of the Society for Applied Research in Memory \& Cognition. Kyoto, Japan.

Nourkova, V.V., Bernstein, D.M., \& Loftus, E.F. (2003). Ėho vzryvov: sravnitel'nyj analiz vospominanij moskvičej o terrorističeskih aktah $1999 \mathrm{~g}$. (Moskva) i $2001 \mathrm{~g}$. (N'û-Jork) [Echo of Blowing Up: Comparative Analysis of the Recollections about the Terrorist Attacks at 1999 (Moscow) and 2001 (New-York City)]. Psihologičeskij žurnal, 24 (1), 67-74. 
Nourkova, V.V., Bernstein, D.M., \& Loftus, E.F. (2004). Altering Traumatic Memory. Cognition and Emotion, 4, 575-585.

Rubin, D.C., \& Schulkind, M.D. (1997). The Distribution of Autobiographical Memories Across the Lifespan. Memory \& Cognition, 25, 859-866.

Rubin, D.C., Rahhal, T.A., \& Poon, L.W. (1998). Things Learned in Early Adulthood are Remembered Best. Memory \& Cognition, 26, 3-19.

Rubin, D.C., Wetzler, S.E., \& Nebes, R.D. (1986). Autobiographical Memory across the Adult Lifespan. In D.C. Rubin (Ed.), Autobiographical memory (pp. 202-221). New York: Cambridge University Press.

Schuman, H., \& Rogers, W. L. (2004). Cohorts, Chronology, and Collective Memories. Public Opinion Quarterly, 68, 217-254.

Thompson, P. (2000). The Voice of the Past: Oral History. 3d ed. Oxford University Press.

Vitulli, W.F., \& Shepard, H.A. (1996). Time Estimation: Effects of Cognitive Task, Presentation Rate and Delay. Perceptual and Motor Skills, 83, 1387-1394.

Welzer, H. (2002). Das kommunikative Gedächtnis. Eine Theorie der Erinnerung. München. 